\title{
Perancangan Model Wisata Edukasi di Objek Wisata Kampung Tulip
}

\author{
Rahmat Priyanto, Didin Syarifuddin, Sopa Martina \\ STP Ars Internasional, rahmat.rmp@bsi.ac.id
}

\begin{abstract}
Abstrak
Kampung Tulip adalah destinasi wisata yang terletak di kawasan ciwastra Kota Bandung. destinasi wisata ini menwarkan kegiatan berwisata dengan nuansa khas belanda sebagai daya tarik utamanya. Visi utama pengelola Kampung tulip adalah untuk menjadikan destinasi wisata ini sebagai tempat edukasi bagi wisatawan, namun dalam pelaksanaanya masih belum sejalan dengan visi yang ditetapkan. Tujuan dari penelitian ini adalah untuk merancang konsep wisata edukasi bagi destinasi wisata kampong tulip. Jenis penelitian ini adalah adalah deskriptif dengan pendekatan secara kualitataif. Pengambilan data dilakukan melalui observasi, wawancara dan studi dokumentasi. Rancangan model wisata edukasi dalam penelitian terdiri dari metode pembelajaran tutorial dan eksplorasi. Tujuan pembelajaran tutorial adalah untuk memberikan pengetahuan dasar mengenai berbagai hal yang terdapat di destinasi wisata. Tujuan pembelajaran eksplorasi adalah untuk meningkatkan pengetahuan dan pemahaman wisatawan dengan melihat secara langsung objek pembelajaran tersebut.
\end{abstract}

Kata kunci : Wisata Edukasi, Pembelajaran Tutorial, Eksplorasi

\begin{abstract}
Kampung Tulip is a tourist destination located in ciwastra Bandung. This destination offers travel activities in Dutch nuances as the main attraction. The main vision of Kampung Tulip managers is to make this destination as a place of education for tourists, but in the implementation is still not in line with the vision set. The purpose of this study is to design the concept of educational tourism for Kampong Tulip. The type of this research is descriptive with a qualitative approach. Data collection is done through observation, interview and documentation study. The design of educational tourism model in research consists of tutorial learning and exploration learning method. The purpose of tutorial learning is to provide basic knowledge about the various things found in tourist destinations. The purpose of exploratory learning is to improve the knowledge and understanding of tourists by looking directly at the learning object.
\end{abstract}

Keywords : Educational Tourism, Tutorial Learning, Exploration.

\section{Pendahuluan}

Pariwisata saat ini menjadi salah satu industri yang berkembang pesat di Indonesia, melalui berbagai rencana pembangunan dan pengembangan pariwisata yang dilakukan pemerintah, maka pariwisata diharapkan dapat terus tumbuh secara signifikan agar mampu meningkatkan perekonomian negara melalui kegiatan pariwisata. Lebih jauh pengeloaan pariwisata yang baik akan memberikan dampak 
positif bagi berbagai sektor industri lainya, sehingga manfaat akan keberadaan pariwisata dapat dirasakan oleh masyarakat banyak. Sektor pariwisata merupakan sektor yang potensial untuk dikembangkan sebagai salah satu sumber pendapatan asli daerah dan pendapatan nasional dalam upaya meningkatkan kesejahteraan dan kemakmuran rakyat (www.nasional.kompas.com,2017)

Pariwisata menjadi pilar proses pembangunan, karena merupakan salah satu kegiatan ekonomi yang dominan dalam kerangka pembangunan ekonomi (Wijayanti, 2017a). Pengembangan pariwisata di suatu daerah yang dikelola dengan baik terbukti mampu memberikan kontribusi yang signifikan bagi pembangunan daerah. Pariwisata terbukti memberi dampak positif bagi kehidupan ekonomi masyarakat seperti : menciptakan peluang kerja baru, meningkatkan kesempatan berusaha, meningkatkan pendapatan masyarakat lokal, meningkatkan pendapatan daerah melalui retrubusi dan pajak dan lain sebagainya (Hermawan, 2016).

Kampung Tulip sebagai destinasi wisata baru di Kota Bandung, menawarkan daya tarik berwisata dengan nuansa khas Belanda, dimana konsep ini merupakan bentuk wisata yang relatif masih baru di Kota Bandung. Di dalam area Kampung Tulip seluas $\pm 800 \mathrm{~m} 2$, pengelola membangun lansekap destinasi wisata yang didominasi oleh berbagai jenis tanaman, danau buatan dan bangunan Belanda dengan ciri khasnya adalah keberadaan kincir angin. Selain itu untuk memenuhi kebutuhan wisatawan, pengelola wisata menyediakan berbagai fasilitas penunjang kepariwisataan seperti kafé, photoboot, sewa baju, terapi ikan dan lain sebagainya.

Segmentasi wisatawan yang berkunjung ke Kampung Tulip didominasi oleh kalangan pelajar dan remaja, mereka berkunjung ke Kampung Tulip dengan tujuan untuk melaksanakan kegiatan study tour ataupun hanya untuk eksis saja melalui dokumentasi yang diupload ke media sosial. Dengan semakin berkembangnya teknologi informasi, maka pengelola Kampung Tulip memanfaatkan media sosial sebagai metode utama kegiatan pemasaranya.

Visi utama pengelola Kampung Tulip adalah untuk menjadikan destinasi wisata ini sebagai tempat edukasi bagi wisatawan, pengelola ingin memberikan pengetahuan mengenai berbagai hal dari Belanda, terutama bagi segmentasi wisatawan pelajar. Berdasarkan hasil wawancara dan observasi, pelaksanaan visi Kampung Tulip sebagai tempat tujuan wisata edukasi belum berjalan dengan baik, lebih jauh pengelola wisata Kampung Tulip belum memahami secara mendalam mengenai apa itu konsep wisata edukasi, sehingga arah pengelolaan dan pengembangan destinasi masih belum sejalan dengan visi yang ingin dicapai.

Sejatinya wisata edukasi merupakan konsep wisata yang bernilai positif, dimana konsep ini memadukan antara kegiatan pembelajaran dengan kegiatan wisata. Wisata edukasi adalah kegiatan pembelajaran yang bersifat non formal, sehingga tidak kaku seperti kegiatan pembelajaran di dalam kelas. Selain itu dalam pelaksanaanya, konsep ini lebih mengarah kepada konsep edutainment, yaitu belajar disertai dengan kegiatan yang menyenangkan. Tujuan utama dari wisata edukasi adalah memberikan kepuasan yang maksimal sekaligus pengetahuan baru kepada wisatawan.

Wisata edukasi adalah suatu program dimana pengunjung dalam kegiatan wisata khususnya anak-anak tersebut melakukan perjalanan wisata pada kawasan wisata 
dengan tujuan utama men-dapatkan pengalaman belajar secara langsung yang terkait dengan kawasan wisata yang dikunjungi. (Soepardi Harris, Atie Ernawati, Rita Laksmitasari : 2014)

Dalam upaya untuk mencapai visi Kampung Tulip sebagai destinasi tujuan wisata edukasi di Kota Bandung, maka dibutuhkan model rancangan yang tepat dalam pengelolaanya, sehingga arah pengembangan destinasi kedepanya dapat sejalan dengan visi yang ditetapkan. Penelitian ini ditujukan untuk merancang konsep wisata edukasi yang sesuai dengan kondisi dan keadaan di destinasi wisata Kampung Tulip.

\section{Kajian Pustaka}

Edukasi atau disebut juga dengan pendidikan merupakan segala upaya yang direncanakan untuk mempengaruhi orang lain baik individu, kelompok, atau masyarakat sehingga mereka melakukan apa yang diharapkan oleh pelaku pendidikan (Notoadmojo, 2003). Pendidikan merupakan suatu kebutuhan bagi setiap orang, maka dibutuhkan metode penyampaian yang menarik dan menyenangkan, sehingga proses pendidikan dapat berjalan secara maksimal. Kegiatan pembelajaran dapat dikombinasikan dan dipadukan dengan berbagai kegiatan lainya, sehingga mampu mengakomodir berbagai aspek dalam satu kegiatan, salah dapat dipadukan dengan kegiatan wisata.

Menurut Fandeli (2001), wisata adalah perjalanan atau sebagai dari kegiatan tersebut dilakukan secara sukarela serta bersifat sementara untuk menikmati objek dan daya tarik wisata.

Wisata memiliki karakteristik - karakteristik antara lain :

1. Bersifat sementara, bahwa dalam jangka waktu pendek pelaku wisata akan kembali ke tempat asalnya.

2. Melibatkan komponen - komponen wisata, misalnya sarana transportasi, akomodasi, restoran, objek wisata, toko cinderamata dan lain-lain.

3. Umumnya dilakukan dengan mengunjungi objek wisata dan atraksi wisata.

4. Memiliki tujuan tertentu yang intinya untuk mendapatkan kesenangan.

5. Tidak untuk mencari nafkah ditempat tujuan, bahkan keberadaannya dapat memberikan kontribusi pendapatan bagi masyarakat atau daerah yang dikunjungi (Suyitno, 2001).

Wisata edukasi merupakan konsep perpaduan antara kegiatan wisata dengan kegiatan pembelajaran. Edu-Tourism atau Pariwisata Edukasi dimaksudkan sebagai suatu program di mana peserta kegiatan wisata melakukan perjalanan wisata pada suatu tempat tertentu dalam suatu kelompok dengan tujuan utama mendapatkan pengalaman belajar secara langsung terkait dengan lokasi yang dikunjungi (Rodger:1998).

Smith dan Jenner (1997) mendeksripsikan wisata edukasi sebagai sebuah tren wisata yang memadukan antara kegiatan rekreasi dan pendidikan sebagai produk pariwisata yang memiliki unsur pembelajaran. Pariwisata edukasi dapat dipadukan dengan berbagai hal lainya dan melayani berbagai macam kepentingan wisatawan, seperti memuaskan rasa keingin tahuan mengenai orang lain, bahasa dan budaya mereka, merangsang minat terhadap seni, musik, arsitektur atau cerita rakyat, 
empati terhadap lingkungan alam, lanskap, flora dan fauna, atau memperdalam daya tarik warisan budaya maupun tempat-tempat bersejarah

Wisata edukasi terdiri dari beberapa sub-jenis, termasuk diantaranya adalah ekowisata, wisata warisan budaya, wisata pedesaan / pertanian, dan pertukaran pelajar antar institusi pendidikan, dimana gagasan bepergian untuk tujuan pendidikan bukanlah hal baru (Gibson, 1998; Holdnak \& Holland, 1996; Kalinowski \& Weiler, 1992)

\section{Metode}

Jenis penelitian yang digunakan adalah penelitian deskriptif dengan pendekatan secara kualitatif, dimana tujuan dari penelitian ini adalah untuk mendeskripsikan perancangan konsep wisata edukasi di objek wisata Kampung Tulip.

Sumber data dalam penelitian ini terdiri dari dua bentuk, yaitu data primer dan data sekunder. Data primer diperoleh melalui kegiatan observasi secara langsung dilapangan dan data hasil wawancara dengen pengelola destinasi wisata Kampung Tulip. Sedangkan data sekunder diperoleh melalui studi terhadap berbagai dokumen dan literature yang berkaitan dengan penelitian.

\section{Hasil dan Pembahasan}

\section{Potensi Wisata Edukasi}

Saat ini bentuk kepariwisataan berbasis edukasi sangat berpotensi untuk terus dikembangkan, hal tersebut didasarkan pada jumlah siswa atau pelajar di Indonesia sebagai segmentasi pasar utama kepariwisataan berbasis edukasi. Untuk jumlah pelajar di kota bandung saja, berdasarkan data statistic BPS di tahun 2016, terdapat total 460.656 pelajar, jumlah tersebut terdiri dari 231174 sebagai pelajar sekolah dasar (SD), 110218 sebagai pelajar sekolah menengah pertama (SMP) dan 119264 sebagai pelajar setara sekolah menengah atas (SMA). Dengan potensi wisatawan sebesar itu, maka kepariwisataan berbasis edukasi akan semakin potensial untuk terus dikembangkan.

\section{Perancangan Model Wisata Edukasi di Kampung Tulip}

Rancangan model wisata edukasi dalam penelitian ini diadaptasi dari penelitian Anukrati Sharma (2015), dimana model ini mengkombinasikan antara kegiatan pembelajaran secara tutorial dengan kegiatan eksplorasi di tempat. Tahapan dalam model ini diawali dengan kegiatan pembelajaran tutorial, yaitu wisatawan diberikan bekal pengetahuan dasar mengenai berbagai hal yang terdapat di objek, kemudian dilanjutkan dengan peningkatan pemahaman wisatawan melalui kegiatan eksplorasi secara langsung di tempat. Untuk lebih jelas dapat dilihat pada gambar berikut : 


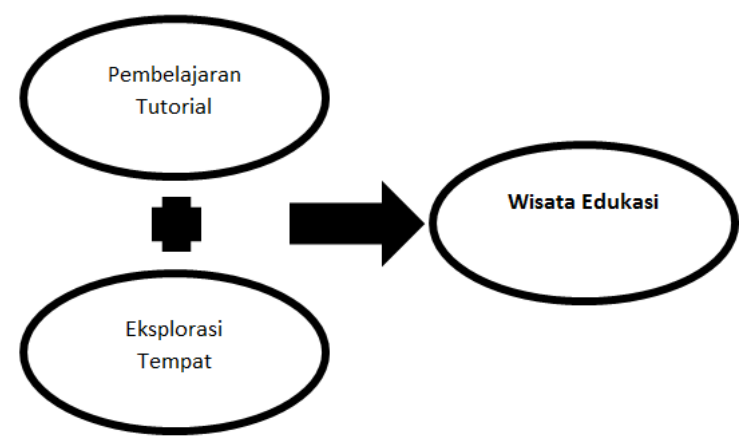

Gambar 1. Rancangan Model Wisata Edukasi Sumber : Anukrati Sharma (2015)

\section{Tutorial Learning}

Ahmadi (1997: 73), berpendapat bahwa tutorial adalah bimbingan pembelajaran dalam bentuk pemberian bimbingan, bantuan, petunjuk arahan dan motivasi agar para siswa belajar secara efisien dan efektif.

Pengapliaksian konsep pembelajaran tutorial di Kampung tulip dapat dimulai dengan mempersiapkan konten-konten informasi apa saja yang ingin disampaikan kepada wisatawan, konten informasi tersebut harus jelas dan mudah dipahami oleh wisatawan. Apabila dikaitkan dengan nuansa Belanda sebagai daya tarik utama yang ditawarkan, maka pengelola dapat mempersiapkan berbagai konten informasi yang terkait dengan Negara Belanda.

Langkah-langkah dalam pembelajaran tutotial dapat dilakukan melalui

1. Menyampaikan pengetahuan dasar mengenai Negara belanda kepada wisatawan, konten informasi tersebut bisa berupa sejarah, sapaan atau perkenalan dalam bahasa belanda, budaya maupun adat istiadat yang terdapat di Belanda, dan berbagai hal lainya yang menjadi ciri khas dari Negara belanda.

2. Dalam upaya untuk menciptakan proses kegiatan belajar yang aktif, maka pengelola Kampung Tulip harus mampu menyediakan pemandu yang atraktif dan komunikatif, yaitu seorang pemandu yang mampu memancing respon dan minat wisatawan untuk diskusi maupun bertanya, sehingga proses kegiatan pembelajaran tidak berjalan hanya searah saja.

Terdapat beberapa kriteria yang harus diperhatikan dalam kegiatan memandu wisatawa, diantaranya:

a. Kemampuan untuk mengungkap kebenaran melalui informasi yang dimiliki.

b. Pemanfaatan informasi untuk menunjukkan keterkaitan antar objek yang sedang diinformasikan kepada para pengunjung. Keterkaitan ini berbeda untuk kelompok pengunjung yang berbeda, misalnya antara anak-anak dengan manusia dewasa, atau antara wisatawan Jepang dengan wisatawan Eropa atau domestik. Mengkaitkan sesuatu yang ditafsirkan dengan keseharian kelompok pengunjungnya

c. Kemampuan untuk membujuk agar pengunjung menjadi tertarik, melalui keterampilan dan media komunikasi untuk menarik perhatian. Interpreter harus memiliki pemahaman tentang ketertarikan (interest) pengunjung. 
d. Menyampaikan penafsiran secara utuh, tidak memberikan kesan bahwa kita hanya sekedar tahu tetapi paham betul tentang apa yang sedang ditafsirkan (Dirgantara, n.d.).

3. Untuk menunjang kegiatan pembelajaran yang menarik, maka pengelola wisata dapat menambahkan media pendukung, seperti gambar, foto atau ilustrasi lainya, sehingga mampu meningkatkan pemahaman wisatawan mengenai konten informasi yang disampaikan.

\section{Eksplorasi Tempat}

Tujuan dari metode eksplorasi ini adalah agar pengunjung mengenal dan melihat secara langsung objek yang disampaikan dalam pembelajaran tutorial. Dalam menunjang kegiatan pembelajaran eksplorasi, maka terdapat beberapa hal yang dapat dilakukan oleh pengelola wisata Kampung Tulip, yaitu :

1. Menciptakan sirkulasi alur pergerakan wisatawan, yaitu pengelola wisata mengarahkan pola pergerakan wisatawan, dimulai dari mereka masuk sampai mereka keluar dari Kampung Tulip. Tujuan dari sirkulasi ini adalah untuk menciptakan pergerakan wisatawan yang tertib dan lancar, wisatawan diarahkan untuk mengeksplorasi seluruh tempat dan fasilitas yang terdapat di dalam area wisata Kampung Tulip. Konsep sirkulasi adalah membagi jalur sirkulasi berdasarkan kegunaanya (Simond, 1983).

Menyediakan fasilitas untuk menunjang kegiatan wisata edukasi di Kampung Tulip. Pengelola wisata dapat menyediakan papan informasi di berbagai lokasi area objek untuk menunjang kegiatan pembelajaran, papan penunjuk arah wisatawan, atau media lain yang mampu mempermudah wisatawan dalam memahami konten pengetahuan yang disampaikan. Fasilitas wisata adalah segala sesuatu yang bersifat melayani dan mempermudah kegiatan atau aktivitas pengunjung yang dilakukan dalam rangka mendapatkan pengalaman rekreasi ( Marpaung 2002).

\section{Simpulan dan Rekomendasi}

Wisata edukasi merupakan suatu konsep pengelolaan kepariwisataan yang memadukan antara kegiatan wisata dengan kegiatan edukasi. Tujuan dari konsep ini agar wisatawan mendapatkan pembelajaran secara langsung di objek wisata, dalam hal ini yaitu memahami mengenai kebudayaan, bangunan dan berbagai hal lainya mengenai Belanda.

Rancangan model pengelolaan wisata edukasi dalam penelitian ini menggunakan 2 pendekatan, yaitu melalui metode pembelajaran tutorial dan metode pembelajaran eksplorasi. Dalam metode pembelajaran tutorial wisatawan diberikan pengetahuan dasar mengenai berbagai hal yang terdapat di objek wisata, kemudian dilanjutkan dengan kegiatan eksplorasi untuk meningkatkan pengetahuan dan pemahaman wisatawan dengan melihat dan menganalisis secara langsung objek pembelajaran tersebut.

\section{Daftar Pustaka}

Dirgantara, A. R. (n.d.). Peran Interpreter dalam Kegiatan Geowisata: Studi Kasus Gunung Tangkuban Perahu. 
Fandeli, C. 2001. Dasar-Dasar Manajemen Kepariwisataan Alam. Yogyakarta:Liberty.

Gibson, H. (1998) The educational tourist. Journal of Phvsical Education. Recreation and Dance, 69 (4),32-34.

Hermawan, H. (2016). Dampak Pengembangan Desa Wisata Nglanggeran Terhadap Ekonomi Masyarakat Lokal. Jurnal Pariwisata, III(2).

Holdnak, A., \& Holland, s. (1996) Edutourism: vacationing to learn: Parks and Recreation, 72-75.

Kalinowski, K., \& Weiler, B. (1992) Review. Educational travel. In B. Weiler and C. Hall (Eds. ), Special Interest Tourism. London: Bellhaven.

Marpaung. 2002. Pengetahuan Kepariwisataan.Bandung: Alfabeta.

Notoatmodjo, Soekidjo. 2003. Pendidikan Dan Perilaku Kesehatan. Rineka Cipta. Jakarta.

Rodger, 1998. Leisure, Learning and Travel, Journal of Physical Education, 69 (4): hal 28.

Sharma, Anukrati. 2015. Educational Tourism : Strategy for Sustainable Tourism Development with reference of Hadauti and Shekhawati Regions of Rajasthan, India.

Simond, J.O. 1983. Landscape Architecture. McGraw-Hill Book Co, NewYork.

Smith, C. \& Jenner, P. (1997). Educational tourism. Travel \& Tourism Analyst, 3, 60-75

Soepardi Harris, Atie Ernawati, Rita Laksmitasari. 2014. Revitalisasi Taman Wisata Sangraja Menjadi Pusat Wisata Edukasi dan Kebudayaan di Majalengka. Prosiding Temu Ilmiah IPLBI 2014

Suyitno. (2001). Perencanaan Wisata. Yogyakarta: Kanisius.

Wijayanti, A. (2017a). Analisis Dampak Pengembangan Desa Wisata Kembang Arum Terhadap Perekonomian Masyarakat Lokal. Tesis. Sarjana Wiyata Tamansiswa Yogyakarta.

http://nasional.kompas.com/read/2017/04/25/06560531/kemendikbud.dukung.pemda.kemban gkan.obyek.wisata.berbasis.kebudayaan 